\title{
A retrospective study of urological injuries during obstetrics and gynecological procedures
}

\author{
Sunil Kumar Samal, Setu Rathod*, Kalaivani Thangavel
}

Department of Obstetrics and Gynecology, Mahatma Gandhi Medical College and Research Institute, Pondicherry, India

Received: 06 June 2020

Accepted: 09 June 2020

*Correspondence:

Dr. Setu Rathod,

E-mail: seturathod@gmail.com

Copyright: () the author(s), publisher and licensee Medip Academy. This is an open-access article distributed under the terms of the Creative Commons Attribution Non-Commercial License, which permits unrestricted non-commercial use, distribution, and reproduction in any medium, provided the original work is properly cited.

\begin{abstract}
Background: Urological injury in obstetrics and gynaecology are not uncommon because there is a close anatomical association between reproductive and urological system. The objective of this study was to find out the incidence and types of urological injuries in obstetric and gynaecological procedures, clinical presentation and various management option in a tertiary care hospital.

Methods: The study was a retrospective analysis of all obstetric and gynecological surgeries over a period of 6 years from January 2014 to December 2019. Cases with the documented urological injuries during these procedures were analyzed further.

Results: Total 8595 patients had undergone different obstetrics and gynecology procedures, out of which 5429 were obstetrics and 3166 were gynecology surgeries. Out of 3166 of gynecology procedures, there were 16 cases $(0.5 \%)$ of bladder injuries and one case $(0.03 \%)$ of ureteric injury. Out of 5429 cases of obstetric procedures there were 11 $(0.2 \%)$ cases of bladder injury and one case $(0.01 \%)$ of ureteric injury.

Conclusions: The incidence urological injuries during obstetrics and gynecological procedures are rare but the morbidity associated these are significant. Therefor surgeons should be more cautious and high degree of suspicion can help in early diagnosis and avoid the sequel.
\end{abstract}

Keywords: Complications, Obstetrics and gynecological procedures, Urologic injury

\section{INTRODUCTION}

Urological injury in obstetrics and gynecology are not uncommon because there is a close anatomical association between reproductive and Urological system. This is evidenced by the fact that $75 \%$ of iatrogenic urinary tract injuries are due to gynecologic procedures. ${ }^{1}$ The incidence of urological injuries in gynecologic procedures is 0.2 to $1 \%$ of all gynecologic procedures and pelvic operations. ${ }^{2}$ Although the incidence of urological injuries during obstetrics and gynecology procedures are small in number but the associated morbidity is significant in the form of haemorrhage followed by blood transfusion, longer operative time, more febrile morbidity, longer hospital stay and sometimes may need second surgery. The etiology of urological injury in obstetrics and gynecology procedures depend upon type of surgery, presence of adhesion due to previous surgery, altered pelvic anatomy due to endometriosis and severe pelvic inflammatory disease, previous radiation therapy, location and size of cervical or broad ligament fibroids and complication like severe intraoperative bleeding. ${ }^{3}$

A regular review of these iatrogenic urological injuries will give information about their recent incidence, changing trends, the time of diagnosis, the overall morbidity observed and available management options. With this aim, this retrospective study of all the urologic injuries observed during various obstetric and gynecological procedures was carried out. 


\section{METHODS}

The study was a retrospective observational study done in Mahatma Gandhi Medical College and Research Institute, Pondicherry from January 2014 to December 2019 (6 years).

\section{Inclusion criteria}

- The cases who had undergone various obstetrics and gynecological procedures during this period.

- The different gynecological procedures were total abdominal hysterectomy (TAH), total laparoscopic hysterectomy (TLH) or laparoscopic assisted vaginal hysterectomy (LAVH), non-descent vaginal hysterectomy (NDVH), vaginal hysterectomy with or without pelvic floor repair $(\mathrm{VH})$, radical hysterectomy (RH), laparotomy (for ovarian cystectomy, salphingectomy, staging laparotomy), diagnostic hysterolaproscopy (DHL), myomectomy, Fothergill's surgery, interval sterilization and vault Prolapse surgery. The different obstetrics procedures were lower segment caesarean section (LSCS), Peripartum hysterectomy, hysterotomy and puerperal sterilization.

\section{Exclusion criteria}

- The minor obstetric and gynecological procedures where the possibility of urologic injury is almost negligible like medical termination of pregnancy, cervical encircalage and gynecological procedures like dilatation and curettage, conization and laparoscopic tubal ligation.

The data were collected from the records kept in labour ward, operation theatre and medical record section.

\section{Statistical analysis}

The data were analyzed critically. Prior clearance was taken before commencement of this study.

\section{RESULTS}

Table 1 and 2 showed that total 8595 patients had undergone different obstetrics and gynaecology procedures, out of which 5429 were obstetrics and 3166 were gynaecology surgeries. Table 1 revealed that out of 3166 of gynaecology procedures, there were 16 cases $(0.5 \%)$ of bladder injuries and one case $(0.03 \%)$ of ureteric injury. Most no of bladder injury cases (6, $0.62 \%)$ and the single ureteric injury case happened during total abdominal hysterectomy. Table 2 showed that out of 5429 cases of obstetric procedures there were $11(0.2 \%)$ cases of bladder injury and one case $(0.01 \%)$ of ureteric injury. Most number of bladder injury cases (9.0.18\%) and the single ureteric injury cases happened during LSCS. Table 3 revealed different risk factors of urological injuries including previous caesarean section, second stage LSCS, altered anatomy due to bleeding, adherent placenta praevia, dense adhesion due to endometriosis and PID, procidentia and cervical fibroid. Most common risk factor for urologic injury in obstetrics and gynaecology procedure was previous caesarean section $(41 \%)$. No identifiable cause was found in $35.9 \%$ of cases.

Table 1: Incidence of urological injuries in gynecological procedures.

\begin{tabular}{|ll|ll|}
\hline Procedures & $\begin{array}{l}\text { Total } \\
\text { number } \\
\text { of cases }\end{array}$ & $\begin{array}{l}\text { Bladder } \\
\text { injury } \\
(\%)\end{array}$ & $\begin{array}{l}\text { Ureteric } \\
\text { injury } \\
(\%)\end{array}$ \\
\hline $\begin{array}{l}\text { Total abdominal } \\
\text { hysterectomy (TAH) }\end{array}$ & 960 & $6(0.62 \%)$ & $1(0.1 \%)$ \\
\hline TLH/LAVH & 124 & $2(1.6 \%)$ & 0 \\
\hline $\begin{array}{l}\text { Non-decent vaginal } \\
\text { hysterectomy }\end{array}$ & 512 & $2(0.39 \%)$ & 0 \\
\hline $\begin{array}{l}\text { Vaginal } \\
\text { hysterectomy }\end{array}$ & 480 & $3(0.62 \%)$ & 0 \\
\hline $\begin{array}{l}\text { Radical } \\
\text { hysterectomy }\end{array}$ & 74 & $2(2.7 \%)$ & 0 \\
\hline Laparotomy & 300 & $1(0.33 \%)$ & 0 \\
\hline Myomectomy & 120 & 0 & 0 \\
\hline $\begin{array}{l}\text { Diagnostic } \\
\text { hysterolaparoscopy }\end{array}$ & 480 & 0 & 0 \\
\hline $\begin{array}{l}\text { Fothergill- } \\
\text { manchester } \\
\text { operation }\end{array}$ & 44 & 0 & 0 \\
\hline Vault prolapse & 12 & 0 & 0 \\
\hline $\begin{array}{l}\text { Interval } \\
\text { sterilisation }\end{array}$ & 60 & 0 & 0 \\
\hline $\begin{array}{l}\text { Total gynecological } \\
\text { procedures }\end{array}$ & 3166 & $16(0.5 \%)$ & $1(0.03 \%)$ \\
\hline
\end{tabular}

Table 2: Incidence of urological injuries in obstetrics procedures.

\begin{tabular}{|l|lll|}
\hline Procedures & $\begin{array}{l}\text { Total } \\
\text { number } \\
\text { of cases }\end{array}$ & $\begin{array}{l}\text { Bladder } \\
\text { injury }(\%)\end{array}$ & $\begin{array}{l}\text { Ureteric } \\
\text { injury }(\%)\end{array}$ \\
\hline LSCS & 4812 & $9(0.18 \%)$ & $1(0.02 \%)$ \\
\hline $\begin{array}{l}\text { Peripartum } \\
\text { hysterectomy }\end{array}$ & 5 & $2(40 \%)$ & 0 \\
\hline Hysterectomy & 12 & 0 & 0 \\
\hline $\begin{array}{l}\text { Puerperal } \\
\text { sterilization }\end{array}$ & 600 & 0 & 0 \\
\hline $\begin{array}{l}\text { Total } \\
\text { Obstetrics } \\
\text { Procedures }\end{array}$ & 5429 & $11(0.2 \%)$ & $1(0.01 \%)$ \\
\hline
\end{tabular}

In Table 4, all gynecologic case with urological injury were analysed in detail. Out of the 6 bladder injury cases during total abdominal hysterectomy, 5 cases diagnosed intraoperatively and primary repair done with 2-0 vicyl suture. One case of bladder injury presented postoperatively as continuous urine leak and diagnosed as 
vescicovaginal fistula (VVF) and repair done. Indwelling foleys catheter were kept for 10-14 days in primary repair and 14-21 days in VVF repair cases. Out of two cases of bladder injury during total laparoscopic hysterectomy (TLH) or laparoscopic assisted vaginal hysterectomy (LAVH) one case diagnosed intra-operatively and laparotomy followed by primary repair done. Another case was presented with VVF on $8^{\text {th }}$ day post-op followed by secondary VVF repair was done. Out of the two cases of bladder injury during non-descent vaginal hysterectomy (NDVH), all two were diagnosed intraoperatively and primary repair was done. Out of three cases of bladder injury during vaginal hysterectomy and pelvic floor repair, two case diagnosed intra op followed by primary repair done. One case presented with urine leak on $10^{\text {th }}$ post-op day followed by secondary VVF repair done. Two cases of VVF were found during radical hysterectomy and secondary VVF repair was done after 3 months. One case of ureteric injury was diagnosed intra-operatively at the time of $\mathrm{TAH}$ in a case of severe endometriosis followed by ureteric reimplantation done.

Table 3: Risk factors for urological injuries.

\begin{tabular}{|ll|l|}
\hline Risk factors & Number & Percentage \\
\hline Previous caesarean section & 16 & $41 \%$ \\
\hline Second stage LSCS & 2 & $5.2 \%$ \\
\hline $\begin{array}{l}\text { Altered anatomy due to } \\
\text { bleeding }\end{array}$ & 2 & $5.2 \%$ \\
\hline Adherent placenta praevia & 1 & $2.5 \%$ \\
\hline $\begin{array}{l}\text { Dense adhesion due to } \\
\text { endometriosis and PID }\end{array}$ & 2 & $5.2 \%$ \\
\hline Procidentia & 1 & $2.5 \%$ \\
\hline Cervical fibroid & 1 & $2.5 \%$ \\
\hline No identifiable cause & 14 & $35.9 \%$ \\
\hline Total & 39 & $100 \%$ \\
\hline
\end{tabular}

Table 4: Analysis of gynecological cases with urological injury.

\begin{tabular}{|c|c|c|c|}
\hline Surgical procedures & Stage of identification & Treatment modality & Duration of hospital stay \\
\hline \multicolumn{4}{|l|}{ Bladder injury } \\
\hline \multirow{2}{*}{ TAH (6) } & 5: Intra-op & 5: Primary repair & \multirow{2}{*}{ 14-21 days } \\
\hline & 1: Post-op & 1: VVF repair & \\
\hline \multirow{2}{*}{ TLH/LAVH (2) } & 1: Intra-op & 1: Laparotomy and primary repair & \multirow{2}{*}{ 14-21 days } \\
\hline & 1: Post-op & 1: VVF repair & \\
\hline NDVH (2) & 2: Intra-op & All primary repair & 10-14 days \\
\hline \multirow{2}{*}{ VH (3) } & 2: Intra-op & 2: Primary repair & \multirow{2}{*}{ 14-21 days } \\
\hline & 1: Post-op & 1: VVF repair & \\
\hline Radical hysterectomy (2) & 2: Post-op & 2: VVF repair & 14-21 days \\
\hline Laparotomy (1) & 1: Intra-op & 1: Primary repair & 10-14 days \\
\hline \multicolumn{4}{|l|}{ Ureteric injury } \\
\hline TAH (1) & 1: Intra-op & 1: Ureteric reimplantation & 14 days \\
\hline
\end{tabular}

Table 5: Analysis of obstetrics cases with urological injury.

\begin{tabular}{|llll|}
\hline Surgical procedures & Stage of identification & Treatment modality & Duration of hospital stay \\
\hline Bladder injury & & & \\
\hline LSCS (9) & 9: Intra-op & 9: primary repair & $10-14$ days \\
\hline Peripartum hysterectomy (2) & 2: Intra-op & 2: primary repair & $14-21$ days \\
\hline Ureteric injury & & & \\
\hline LSCS (1) & 1: Post-op & $\begin{array}{l}\text { 1: laparotomy and ureteric } \\
\text { reimplantation }\end{array}$ & $14-21$ days \\
\hline
\end{tabular}

In Table 5, all obstetric cases with urological injury were analysed in detail. Out of the 12 cases of bladder injury happened during LSCS, all cases were diagnosed intraoperatively followed by primary repair was done with 2-0 vicryl. Indwelling foleys catheter was kept for 10 to 14 days. Two cases of bladder injury observed during emergency peripartum hysterectomy intraoperatively followed by primary repair was done. One case of ureteric injury (Kinking of ureter) was detected in one post LSCS case on $7^{\text {th }}$ post-op day followed by laparotomy and ureteric reimplantation was done.

\section{DISCUSSION}

The incidence of bladder and ureteric injury during gynecology procedures in this study were $0.5 \%$ and $0.03 \%$ respectively. The incidence of bladder and ureteric 
injuries in obstetric procedures were $0.2 \%$ and $0.01 \%$ respectively. The overall incidence of urological injuries as reported in previous studies varies from $0.5-1.5 \% .^{4,5}$ Ozdemir et al showed that incidence of bladder and ureteric injuries in gynecologic surgeries as $1.23 \%$ and $0.11 \%$ respectively, whereas in obstetric procedures incidence of bladder injury was reported as $0.67 \%$ and ureteric injury as $0.33 \% .6$ In this study, authors observed two cases of bladder injury out of five peripartum hysterectomies, which was the maximum incidence across all surgeries. In literature, other studies also reported about high incidence bladder and ureteric injuries of $6.1 \%$ and $1.5 \%$ respectively for obstetric hysterectomies..$^{7-9}$ The possible explanation proposed in these cases are difficulty in identifying anatomy due to presence of blood in the surgical field and atonic uterus. ${ }^{9}$ In gynecological procedures, radical hysterectomy for gynecologic malignancy was associated with maximum incidence of $2.7 \%$, which is similar to incidences reported in literature. ${ }^{10,11}$ The possible explanation of urological injury during these procedures was due to extensive dissection performed during these surgeries and pelvic adhesion caused by gynecologic cancer. ${ }^{11}$ In benign gynecology procedures, the highest incidence of bladder injury observed in laparoscopic procedures like TLH/LAVH followed by simple TAH $(0.62 \%)$ and VH $(0.62 \%)$ cases. The possible explanation was attributed to steep learning curve for laparoscopic procedures. In literature, other studies also suggest laparoscopic surgeries have increased the incidence of urologic injuries and with achievement of the learning curve, though the frequency of bladder injury has declined but that of ureteric injury is still high. ${ }^{11,12}$ In this study, authors observed that there were 27 cases of bladder injuries compared to two cases of ureteric injuries in overall all obstetrics and gynecology procedures. Among the cases of bladder injury, 22 cases diagnosed intraoperatively and the remaining five were presented as VVF during post-operative period. The prognosis and outcome of primary repair is good without much late sequels. Hence it is important to identify bladder injuries intra-operatively and perform primary repair to minimize morbidity to the patient. In this study, authors observed two cases of ureteric injury, one during TAH for grade four endometriosis case and another during LSCS for one second stage arrest. The ureteric injury for gynecology procedure was identified intraoperatively and managed by ureteric reimplantation. The other ureteric injury happened during LSCS for second stage arrest was diagnosed postoperatively on $7^{\text {th }}$ POD and managed by laparotomy with ureteric reimplantation. This concurs with other reported cases of ureteric injuries in literature, which also states ureteric injuries are rarely diagnosed intraoperatively. ${ }^{12,13}$ Intra-operatively diagnosed cases of ureteric injuries are usually more easily repaired at the time without the need for a second surgical intervention. ${ }^{8,11}$ Any delay in the diagnosis leads to increase in morbidity, prolonged hospital stay and repeat surgery. Usually ureteric injuries are not always easy to diagnose and suspicion should be raised in patients with unexplained hematuria, fever, abdominal or flank pain and poor urine output. ${ }^{9,12}$ Regardless of the cause of urological injury and damage, quick radiological investigation in the form of intravenous urography or contrast-enhanced computed tomography is ultimately required for diagnosis to prevent delay in treatment. ${ }^{13} \mathrm{In}$ this study, five cases of VVF observed in gynecology procedures. All cases needed secondary repair, with the help of urology surgeons. The possible etiology for these urological injuries is presence of adhesion between bladder and previous LSCS uterine scar with obliteration of safe surgical plane. ${ }^{7,12}$ Gynecological malignancy, carcinomas, large cervical fibroid, procidentia, LSCS in second stage arrest were other risk factors observed in this study. In literature, previous studies have shown higher incidence of urologic injuries in surgery for prolapse and procidentia. ${ }^{11,13}$ It also has been observed that most of the cases of ureteric injuries happened in lower third of ureter and most likely were caused by thermal injury during laparoscopy. ${ }^{10,12}$ The most common sites of ureteric injury happened during hysterectomy was along the pelvic wall lateral to the uterine artery, the area of uretero-vesical junction, and the base of infundibulopelvic ligament. ${ }^{9-12}$ Following measures like a thorough knowledge of pelvic anatomy, being close to the uterus when coagulating, intraoperative cystoscopy and dissecting ureter throughout its course in difficult cases are recommended as measures to avoid ureteric injuries.

\section{CONCLUSION}

The incidence urological injuries during obstetrics and gynecological procedures are rare but the morbidity associated these are significant. Bladder injuries are more common, easy to diagnose and easy to manage if diagnosed early. In other hand, ureteric injuries during obstetrics and gynaecology procedures are difficult to diagnose and hence cause more morbidity than bladder injuries. Therefor surgeons should be more cautious and high degree of suspicion can help in early diagnosis and avoid the sequel.

\section{Funding: No funding sources Conflict of interest: None declared \\ Ethical approval: The study was approved by the Institutional Ethics Committee}

\section{REFERENCES}

1. Thompson JD. Operative injuries to the ureter: prevention, recognition, and management. In: Rock JA, Thompson JD. TeLinde's operative gynecology.8th ed. Philadelphia: Lippincott Williams and Wilkins; 1997:1135-1174.

2. Gilmour DT, Dwyer PL, Carey MP. Lower urinary tract injury during gynecologic surgery and its detection by intraoperative cystoscopy. Obstet Gynecol. 1999;94:883-9. 
3. Harkki-Siren P, Sjoberg J, Tiitinea A. Urinary tract injuries after hysterectomy. Obstet Gynecol. 1998;92:113-8.

4. Purandare CN. Urological injuries in gynecology. J Obstet Gynecol India. 2007;57:203-4.

5. Frankman EA, Wang L, Bunker $\mathrm{CH}$, Lowder JL. Lower urinary tract injury in women in the United States, 1979-2006. Am J Obstet Gynecol. 2010;202:495.e1-5.

6. Ozdemir E, Ozturk U, Celen S, Sucak A, Gunel M, Guney G, et al. Urinary complications of gynecologic surgery: iatrogenic urinary tract system injuries in obstetrics and gynecology operations. Clin Exp Obstet Gynecol. 2011;38:217-20.

7. Sahito RA, Memon GA, Khaskheli MS. Urological injuries during obstetrical and gynecological surgeries. Annals. 2011;17:218-22.

8. Lee JS, Choe JH, Lee HS, Seo JT. Urologic complications following obstetric and gynecologic surgery. Korean J Urol. 2012;53:795-9.

9. Adelman MR, Bardsley TR, Sharp HT. Urinary tract injuries in laparoscopic hysterectomy: a systematic review. J Minim Invasive Gynecol. 2014;21:558-66.
10. Vakili B, Chesson RR, Kyle BL, Shobeiri SA, Echols KT, Gist R, et al. The incidence of urinary tract injury during hysterectomy: a prospective analysis based on universal cystoscopy. Am J Obstet Gynecol. 2005;192:1599-604.

11. Berkmen F, Peker AE, Alagol H, Ayyildiz A, Arik AI, Basay S. Treatment of iatrogenic ureteral injuries during various operations for malignant conditions. $\mathbf{J}$ Exp Clin Cancer Res. 2000;19:441-5.

12. Chapron C, Pierre F, Querleu D, Dubuisson JB. Complications of laparoscopy in gynecology. Gynecol Obstet Fertil. 2001;29:605-12.

13. Carley ME, McIntire D, Carley JM, Schaffer J. Incidence, risk factors and morbidity of unintended bladder or ureter injury during hysterectomy. Int Urogynecol J Pelvic Floor Dysfunct. 2002;13(1):1821.

Cite this article as: Samal SK, Rathod S, Thangavel $\mathrm{K}$. A retrospective study of urological injuries during obstetrics and gynecological procedures. Int J Reprod Contracept Obstet Gynecol 2020;9:2746-50. 